\title{
MicroRNAs, as Essential Components of Non-Coding Genome, are Emerging Key Players of Oncogenesis
}

\section{Mustafa Ozen ${ }^{1,2 *}$ and Omer Faruk Karatas ${ }^{1,3}$}

${ }^{1}$ Department of Medical Genetics, Istanbul University Cerrahpasa Medical School, Istanbul, Turkey

${ }^{2}$ Department of Pathology \& Immunology, Baylor College of Medicine, Houston, TX, 77030, USA

${ }^{3}$ Molecular Biology and Genetics Department, Erzurum Technical University, Erzurum, Turkey

MicroRNAs (miRNAs) were originally identified in 1993, when a non-coding small RNA gene, lin-4, has been discovered in a genetic screen utilized to find out genes controlling developmental timing of the nematode, Caenorhabditis elegans larvae $[1,2]$. Findings about lin-4 and other newly discovered small non-coding RNAs having the capacity to alter gene expression post-transcriptionally in a variety of species including mammalians, put forward miRNAs, which, are endogenously synthesized, approximately 22 nucleotide-long, single stranded and non-coding RNAs, as indispensable components of noncoding genome [3-6]. Since their discovery, hundreds of miRNAs have been shown to play essential roles through modulating expression of their validated targets in several biological events both in physiological and pathological conditions [7-9] and they are estimated to regulate the expression of at least $60 \%$ of human genes [10].

MiRNAs have become a very popular subject in cancer research field, since Calin et al. showed the association between miRNAs and cancer for the first time as a result of identifying miR-15-a and miR-161 as localized on a chromosomal region, which is frequently deleted in B-cell chronic lymphocytic leukemia cases [11]. Since then, remarkable achievements have been accomplished concerning miRNAs and their involvement in pathogenesis of distinct cancer types. They has been shown to have either oncogenic or tumor suppressor potential. Recently, among many others, miR-125b, miR-221/222, miR-21, miR-27a and miR-106a are implicated as key oncogenic miRNAs associated with tumorigenesis [12]. Besides, miR-145, miR-34c, and let-7c are known as the most known tumor suppressor miRNAs in carcinogenesis. In addition to their oncogenic and tumor suppressor potencies, miRNAs are reported to be associated with tumor progression and metastasis. Although functions of miRNAs in these processes still remain to be resolved, in distinct cancers, certain miRNAs such as let7c, miR-21, miRr-34a, miR-145 and miR-205 have been implicated as significant effectors in cell migration and metastatic pathways [13-17].

Furthermore, due to several advantages such as not being complex, having no posttranscriptional modification, easy detection of expressional changes, having tissue, body fluid specific profile, being highly conserved amongst human and other model organisms, and their high stability, mature miRNAs are among the ideal candidate biomarkers for characterization of physio-pathological conditions including cancer prognosis. For instance, recently miR-221 in hepatocellular carcinoma has been demonstrated to be associated with prognosis. Moreover, in the same study, increased miR-221 level has been reported to be correlated with tumor size, cirrhosis, tumor stage and poor prognosis [18]. In a different study, high level of miR181a expression was found to be associated with poor prognosis in astrocytoma and miR-181b has been proposed as a biomarker to differentiate high-grade glioblastomas from low-grade tumors [19]. Besides, Wang et al. demonstrated that levels of miR-21, miR-106a and miR-155 levels are elevated and those of miR-126, miR-199a and miR335 are reduced in serum and tissue samples of breast cancer patients with regard to healthy controls [20]. In prostate cancer, miR-26a, miR-195 and let-7i levels in serum were found to be higher in cancer patients compared to benign prostate hyperplasia patients. In another study deregulation of three miRNAs, miR-93, miR-106a and miR-24 in serum samples of in early stage prostate cancer patients compared to healthy controls [21].

Furthermore, knowing the fact that altered miRNA levels are observed in various tumor types and their specific deregulation pattern in distinct tumors make miRNAs come forward as putative therapeutic targets and diagnostic markers. For example, in pancreatic ductal adenocarcinoma cases, in which high levels of miR-21 has been observed, anti-miR-21 treatment resulted in inhibition of proliferation of human pancreatic ductal adenocarcinoma derived cell lines through induction of apoptosis. In addition, chemotherapeutics in combination with anti-miR-21 treatment are suggested to reduce the tumor size [22].

Now, after discovery of more than 2500 identified mature miRNAs in Homo sapiens [23], miRNA expression profiling remains very crucial for understanding the underlying mechanisms of cancer initiation, progression, invasion or metastasis and developing novel and promising therapeutic applications against cancer. Meanwhile, further studies elucidating miRNAs' mechanisms of action are necessary to shed light on how miRNAs function in cancer pathogenesis and to overcome the putative challenges like side effects and problems in delivery to their right targets.

\section{References}

1. Lee RC, Feinbaum RL, Ambros V (1993) The c. Elegans heterochronic gene lin-4 encodes small rnas with antisense complementarity to lin-14. Cell 75: 84354.

2. Olsen $\mathrm{PH}$, Ambros $\mathrm{V}$ (1999) The lin-4 regulatory rna controls developmental timing in caenorhabditis elegans by blocking lin-14 protein synthesis after the initiation of translation. Dev Biol 216: 671-680

3. Reinhart BJ, Slack FJ, Basson M, Pasquinelli AE, Bettinger JC, et al. (2000) The 21-nucleotide let-7 rna regulates developmental timing in caenorhabditis elegans. Nature 403: 901-906.

4. Lagos-Quintana M, Rauhut R, Lendeckel W, Tuschl T (2001) Identification of novel genes coding for small expressed RNAs. Science 294: 853-858.

5. Pasquinelli AE, Reinhart BJ, Slack F, Martindale MQ, Kuroda MI, et al. (2000) Conservation of the sequence and temporal expression of let-7 heterochronic regulatory RNA. Nature 408: 86-89.

6. Nikitina EG, Urazova LN, Stegny VN (2012) Micrornas and Human Cancer Exp Oncol 34: 2-8

7. Iorio MV, Croce CM (2012) Causes and consequences of microrna dysregulation. Cancer J 18: 215-222.

*Corresponding author: Mustafa Ozen, Istanbul University, Cerrahpasa Medical School, Department of Medical Genetics, Fatih, Istanbul, Turkey, Tel: +90 212-4143000-21304; Fax: +90 212-414-3184; E-mail: mozen@bcm.edu

Received October 01, 2013; Accepted October 02, 2013; Published October 07 2013

Citation: Ozen M, Karatas OF (2013) MicroRNAs, as Essential Components of Non-Coding Genome, are Emerging Key Players of Oncogenesis. Mol Biol 2: e112. doi:10.4172/2168-9547.1000e112

Copyright: (C) 2013 Ozen M, et al. This is an open-access article distributed unde the terms of the Creative Commons Attribution License, which permits unrestricted use, distribution, and reproduction in any medium, provided the original author and source are credited. 
8. Karatas OF, Guzel E, Karaca E, Sevli S, Soyucen E, et al. (2013) Microrna profiling in lymphocytes and serum of tyrosinemia type-i patients. Mol Biol Rep 40: $4619-4623$

9. Bayrak OF, Gulluoglu S, Aydemir E, Ture U, Acar H, et al. (2013) Microrna expression profiling reveals the potential function of microrna-31 in chordomas. J Neurooncol.

10. Bartel DP (2009) Micrornas: Target recognition and regulatory functions. Cell 136: 215-233.

11. Calin GA, Dumitru CD, Shimizu M, Bichi R, Zupo S, et al. (2002) Frequent deletions and down-regulation of micro- rna genes mir15 and mir16 at 13q14 in chronic lymphocytic leukemia. Proc Natl Acad Sci. 99: 15524-15529.

12. Sevli S, Uzumcu A, Solak M, Ittmann M, Ozen M (2010) The function of micrornas, small but potent molecules, in human prostate cancer. Prostate Cancer Prostatic Dis 13: 208-217.

13. Gregory PA, Bracken CP, Bert AG, Goodall GJ (2008) Micrornas as regulators of epithelial-mesenchymal transition. Cell Cycle. 7: 3112-3118.

14. Tavazoie SF, Alarcon C, Oskarsson T, Padua D, Wang Q, et al. (2008) Endogenous human micrornas that suppress breast cancer metastasis. Nature 451: 147-152.

15. Watahiki A, Wang Y, Morris J, Dennis K, O’Dwyer HM, et al. (2011) Micrornas associated with metastatic prostate cancer. PLoS One 6: e24950.
16. Wu H, Zhu S, Mo YY (2009) Suppression of cell growth and invasion by mir-205 in breast cancer. Cell Res 19: 439-448.

17. Ozen M, Creighton CJ, Ozdemir M, Ittmann M (2008) Widespread deregulation of microrna expression in human prostate cancer. Oncogene 27: 1788-1793.

18. Li J, Wang Y, Yu W, Chen J, Luo J (2011) Expression of serum mir-221 in human hepatocellular carcinoma and its prognostic significance. Biochem Biophys Res Commun 406: 70-73.

19. Shi L, Cheng Z, Zhang J, Li R, Zhao P, et al. (2008) Hsa-mir-181a and hsa-mir$181 \mathrm{~b}$ function as tumor suppressors in human glioma cells. Brain Res 1236 185-193.

20. Wang F, Zheng Z, Guo J, Ding X (2010) Correlation and quantitation of microrna aberrant expression in tissues and sera from patients with breast tumor. Gynecol Oncol 119: 586-593.

21. Moltzahn F, Olshen AB, Baehner L, Peek A, Fong L, et al. (2011) Microfluidicbased multiplex qrt-pcr identifies diagnostic and prognostic microrna signatures in the sera of prostate cancer patients. Cancer Res 71: 550-560.

22. Sicard F, Gayral M, Lulka H, Buscail L, Cordelier P (2013) Targeting mir-21 for the therapy of pancreatic cancer. Mol Ther 21: 986-994.

23. Kozomara A, Griffiths-Jones S (2011) Mirbase: Integrating microrna annotation and deep-sequencing data. Nucleic Acids Res 39: D152-157. 